\title{
Isolated, Subtle Neurological Abnormalities in Mild Cognitive Impairment Types
}

\author{
Cecilia Camarda, Rosolino Camarda, Carmela Pipia, Delia Azzarello, \\ Emanuele Grassedonio, Gianluca Sottile (D), Giovanna Cilluffo, Paola Torelli
}

\begin{abstract}
Background: Isolated, subtle neurological abnormalities (ISNA) are commonly seen in aging and have been related to cerebral small vessel disease (SVD) and subcortical atrophy in neurologically and cognitively healthy aging subjects. Objective: To investigate the frequency of ISNA in different mild cognitive impairment (MCI) types and to evaluate for each MCI type, the crosssectional relation between ISNA and white matter hyperintensities (WMH), lacunes, caudate atrophy, and ventricular enlargement. Methods: One thousand two hundred fifty subjects with different MCI types were included in the analysis and underwent brain magnetic resonance imaging. WMHs were assessed through two visual rating scales. Lacunes were also rated. Atrophy of the caudate nuclei and ventricular enlargement were assessed through the bicaudate ratio $(\mathrm{BCr})$ and the lateral ventricles to brain ratio ( $\mathrm{LVBr}$ ), respectively. Apolipoprotein E (APOE) genotypes were also assessed. The routine neurological examination was used to evaluate ISNAs that were clustered as central-based signs, cerebellar-based signs, and primitive reflexes. The items of Part-III of the Unified Parkinson's Disease Rating Scale were used to evaluate ISNAs that were clustered as mild parkinsonian signs. Associations of ISNAs with imaging findings were determined through logistic regression analysis. Results: The ISNAs increase with the age and are present in all MCI types, particularly in those multiple domains, and carrying the APOE $€ 4$ allele, and are associated with WMH, lacunes, BCr, and LVBr. Conclusion: This study demonstrates that cortical and subcortical vascular and atrophic processes contribute to ISNAs. Long prospective population-based studies are needed to disentangle the role of ISNAs in the conversion from MCI to dementia.
\end{abstract}

RÉSUMÉ: Des anomalies neurologiques subtiles et isolées associées à différents types de déficience cognitive légère. Contexte: Des anomalies neurologiques à la fois subtiles et isolées sont fréquemment observées chez les personnes vieillissantes. Elles ont été associées à la maladie des petits vaisseaux du cerveau (cerebral small vessel disease) et à une atrophie des structures sous-corticales chez des sujets âgés en santé sur les plans neurologique et cognitif. Objectif: Étudier la fréquence de ces anomalies dans le cas de différents types de déficience cognitive légère ; évaluer, pour chaque type de déficience, la relation transversale entre ces anomalies et des hyper-signaux de la substance blanche, des lacunes cérébrales, l'atrophie du noyau caudé et l'élargissement des ventricules. Méthodes: Au total, 1250 sujets atteints de différents types de déficience cognitive légère ont été inclus dans notre analyse et ont passé un examen d'IRM du cerveau. On a évalué les hyper-signaux de la substance blanche à l'aide de deux échelles d'évaluation visuelle. À noter que les lacunes cérébrales ont également été évaluées. Du côté de l'atrophie du noyau caudé et de l'élargissement des ventricules, ces anomalies ont été mesurées respectivement au moyen de l'index bicaudé (bicaudate ratio) et du ratio volumique ventricule-cerveau (lateral ventricles to brain ratio). Enfin, les génotypes associés à l'apolipoprotéine E (ApoE) ont été examinés. Fait à souligner, des examens neurologiques de routine portant sur les signes du système nerveux central, sur les signes du cervelet et sur les réflexes archaïques ont été utilisés pour tenter de cerner les anomalies évoquées ci-dessus. Des éléments de la partie III de l'échelle UPDRS (Unified Parkinson's Disease Rating Scale) ont été par ailleurs mis à profit pour évaluer les anomalies regroupées au sein de la catégorie des signes bénins de la maladie de Parkinson. Les liens entre ces anomalies et les résultats aux examens d'IRM ont été déterminés à l'aide d'une analyse de régression logistique. Résultats: Ces anomalies neurologiques à la fois subtiles et isolées augmentent en fonction de l'âge et sont présentes parmi tous les types de déficience cognitive légère, en particulier dans ces domaines multiples et chez les sujets porteurs de l'allèle $\epsilon 4$ du gène de l'ApoE. On a vu également qu'elles sont associées à des hyper-signaux de la substance blanche, à des lacunes cérébrales, à l'atrophie du noyau caudé et à l'élargissement des ventricules. Conclusion: Cette étude démontre que les processus vasculaires et atrophiques des structures corticales et souscorticales contribuent à l'apparition d'anomalies neurologiques à la fois subtiles et isolées. Des études prospectives de longue haleine basées sur la population sont toutefois nécessaires pour mieux comprendre le rôle de ces anomalies dans l'évolution des cas de déficience cognitive légère vers la démence.

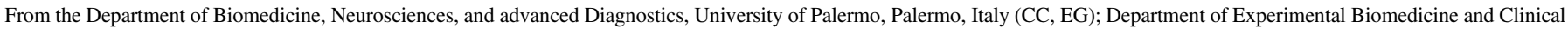

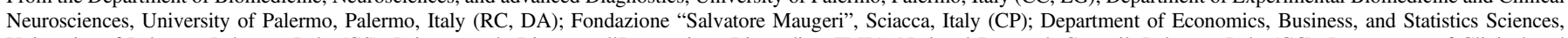

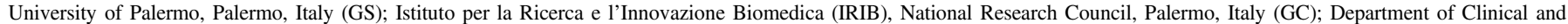
Experimental Medicine, University of Parma, Parma, Italy (PT)

Received May 2, 2019. Final Revisions Submitted August 27, 2019. Date of Acceptance August 31, 2019.

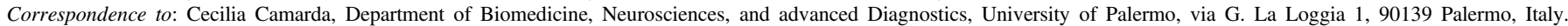

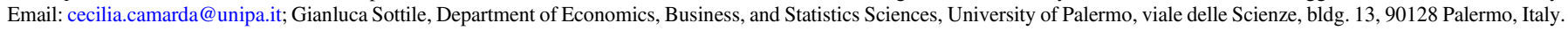
Email: gianluca.sottile@unipa.it 
Keywords: Isolated, subtle neurological abnormalities, Mild cognitive impairment types, White matter hyperintensities, Lacunes, Caudate atrophy, Global cerebral atrophy

doi:10.1017/cjn.2019.293

Can J Neurol Sci. 2020; 47: 77-91

\section{INTRODUCTION}

Mild cognitive impairment (MCI) is a term that refers to a condition in which an essentially spared global cognition and normal or slightly impaired activities of daily living (ADL) coexist with a mild decline of cognitive functions greater than that expected for age and education. ${ }^{1,2}$ Four MCI phenotypes have been recognized ${ }^{2}$ as follows: amnestic MCI single domain (a-MCI), amnestic MCI multiple domain (a-MCImd), nonamnestic MCI single domain (na-MCI), and nonamnestic MCI multiple domain (na-MCImd). Extracellular deposition of $\beta$-amyloid (A $\beta$ ) peptide, intracellular deposition of hyper-phosphorylated tau protein, and atrophy of frontal, parietal, and medial temporal cortices, i.e., neurodegeneration of Alzheimer disease (AD) signature cortical regions, ${ }^{3}$ are the key elements of the pathophysiology of $\mathrm{AD}^{4}$ and $\mathrm{MCI}$ due to $\mathrm{AD}{ }^{5}$ The prevalence of $\mathrm{A} \beta$ positivity among subjects with MCI increases from age 50 to 90 years from $27 \%$ to $71 \%$; nonamnestic MCI types have lower prevalence estimates of $\mathrm{A} \beta$ positivity than amnestic MCI types, but higher than subjects cognitively normal $(\mathrm{CN})$, and both amnestic and nonamnestic MCI are at increased risk for AD. ${ }^{6}$ Concerning tau, MCI and AD individuals have tau accumulation in the basal and mild-temporal, retrosplenial, posterior cingulate, and entorhinal regions greater than $\mathrm{CN}$ individuals $\mathrm{A} \beta$ positive. ${ }^{7}$

The observation that $21.5 \%$ and $35 \%$ of individuals with amnestic and nonamnestic MCI types, respectively, are $\mathrm{A} \beta$ negative, ${ }^{8}$ has suggested that these individuals are not on the AD pathway and that vascular pathology may be one of the possible non-AD causes of MCI. Among vascular pathology, cerebral small vessel disease (SVD) plays a pivotal role. SVD affects the smallest cerebral small vessels, increases throughout the lifespan, ${ }^{9}$ and contributes to the risk of $\mathrm{MCI}^{10}$ and dementia. ${ }^{11}$ White matter hyperintensities (WMH), lacunes, small subcortical infarcts, microbleeds, enlarged perivascular spaces, and central atrophy are the imaging markers of SVD. ${ }^{12}$ Lacunes $^{13}$ and $\mathrm{WMH}^{14}$ disrupting locally the structural integrity of white matter induce thinning of the connected cortical regions through Wallerian degeneration. Lacunes are associated with widespread cortical thinning, atrophy in multiple subcortical structures, and ventricular enlargement. ${ }^{15}$ In subjects with MCI, expansion of the lateral ventricles is associated with atrophy of frontal, parietal, and temporal regions affected by $\mathrm{AD} .{ }^{16}$ Furthermore, age per se is associated with atrophy of the cerebellum, striatum, and prefrontal, parietal, and temporal association cortices. ${ }^{17}$ The pattern of cortical atrophy induced by severe WMH overlaps substantially with the patterns of age-related cortical atrophy and of AD-related cortical atrophy. ${ }^{18}$ Since cortical atrophy induced by WMH drives cognitive decline, ${ }^{19}$ age and SVD may contribute to the onset of cognitive decline through the overlapping atrophy of cortical regions vulnerable to AD pathology.

Cerebral SVD, A $\beta$, tau, and atrophic changes fragmenting over time brain networks into disconnected parts not only contribute to cognitive decline but also contribute to the presentation of a wide range of neurological signs. We have shown that neurologically and cognitively healthy $(\mathrm{NCH})$ aging subjects frequently present at the routine neurological examination isolated, subtle neurological abnormalities (ISNAs) which do not have any immediate diagnostic relevance, cannot be attributed to any definite, overt neurological disease, are associated with atrophy of the caudate nuclei, and with parietal WMH and lacunes, and probably constitute a red flag for future cognitive decline given that they show poor performance in test evaluating global cognition, executive function, and language. ${ }^{20}$ Past reports on neurological signs in MCI have primarily focused on extrapyramidal features, ${ }^{21,22}$ while reports on signs other than extrapyramidal are sparse. Therefore, the aims of our study are: (1) to investigate the prevalence of ISNAs in the four MCI types and (2) to verify whether in the individual MCI types the probability of having ISNAs is differently associated with the topographical location of WMH and lacunes, periventricular WMH (WMH-PV), apolipoprotein E (APOE) $€ 4$ allele, and with two linear measures of central atrophy, ${ }^{12}$ i.e., the bicaudate ratio $(\mathrm{BCr})$ as proxy of subcortical atrophy and the lateral ventricles to brain ratio ( $\mathrm{LVBr}$ ) as proxy of global brain atrophy. In the present paper, the terms "adult", "elderly", "old", and "oldest-old" will be used to indicate people aged $45-64,65-74,75-84$, and $>85$ years, respectively.

\section{Methods \\ Participants}

Data were used from the Cognitive Impairment through Aging (CogItA) study, a hospital-based prospective study focused on normal and pathological aging in middle-aged and older individuals launched in January 2000. CogItA's participants were outpatients self-referred or referred by general practitioners for neurological and/or cognitive screenings to the clinics of the Department of Neurology and Cognitive Disorders of the teaching Hospital (AOUP "P.Giaccone") of the School of Medicine of the University of Palermo, Italy. Details of the inclusion and exclusion criteria of the CogItA study have been reported elsewhere. ${ }^{20}$ Informed consent was obtained from all participants and relatives. The study was approved by the University Hospital ethics committee and complies with the declaration of Helsinki.

According to the published criteria, ${ }^{1,2}$ CogItA participants with preserved global cognition at the Mini-Mental State examination (MMSE score $\geq 23.74$ ), ${ }^{23}$ subjective cognitive concerns, objective impairment in one or more cognitive domains, Clinical Dementia Rating $=0.5,{ }^{24}$ no impaired or minimally impaired functional status on the $\mathrm{ADL}^{25}$ and the instrumental $\mathrm{ADL}$ $(\mathrm{IADL})^{26}$ scales, and no dementia were classified as MCI and categorized as a-MCI, a-MCImd, na-MCI, and na-MCImd. MCI subjects included in the present paper were stroke-free first-ever diagnosed cases $(n=1250)$ aged $45-95$ years (mean age $=70.52 \pm 9.41$ years), who remained in the MCI status for at least 3 years (mean follow-up $=64.98 \pm 28.94$ months). During this period, some of these subjects changed their MCI typology, 
but in the present paper, first-ever MCI diagnoses were considered. Subjects who during the follow-up reverted to normal cognition or converted to dementias different from $\mathrm{AD}$ and vascular dementia, such as dementia with Lewy bodies ${ }^{27}$ or frontotemporal dementia, ${ }^{28}$ were not considered.

\section{Baseline Clinical Assessment}

Participants to the present study underwent an extensive assessment of variables such as demographics, medical history, laboratory tests, neurological and functional examinations, cognitive testing, carotid ultrasonography, and brain magnetic resonance imaging (MRI). Many vascular risk factors (VRFs) and vascular diseases (VDs) were considered and assessed as reported elsewhere. $^{20,29}$ Since multiple VRFs and VDs often coexist, we created the VRF and VD summary scores indicating for each participant the sum of the individual VRFs and VDs that were concurrently present. APOE genotypes were determined by using standard methods. ${ }^{30}$ Participants with at least 1 APOE $€ 4$ allele were classified as APOE $€ 4$ carriers.

\section{Assessment of ISNAs}

All participants underwent a standardized neurological examination reflecting that routinely performed in the clinical practice. Subjects presenting at baseline or during follow-up meaningful neurological signs such as visual field defects, language deficits, cranial nerves deficits, hemimotor and hemisensory dysfunction, brachial or crural weakness, brachial or crural sensory dysfunction, Babinski sign, spastic rigidity, and hemiplegic gait were excluded. The ISNAs evaluated were: (1) mild dysphagia, (2) slurred speech, (3) central facial weakness, (4) mixed rigidity, i.e., a condition in which spastic and plastic rigidity coexist; (5) hyperreflexia (bilateral increased deep tendon reflexes), (6) reflex asymmetry, (7) tremor (resting tremor and postural/kinetic tremor), (8) plastic rigidity, (9) bradykinesia, (10) gait/balance/axial dysfunction, (11) dysmetria, (12) atactic type gait defined as a gait pattern broadly indicative of cerebellar involvement, and (13) primitive reflexes (PRs), i.e., glabellar tap, snout, palmomental, grasping, and sucking reflexes. ${ }^{31,32}$ To evaluate tremor, rigidity, bradykinesia, and gait/balance/axial dysfunction, collectively called mild parkinsonian signs (MPSs), ${ }^{33}$ the items of motor section of the Unified Parkinson's Disease Rating Scale ${ }^{34}$ were used and were considered present when any one of the following conditions was met: (1) two or more items with a score of 1 ; or (2) one item with a score $\geq 2 .^{21}$ The ISNA were dichotomised as absent $($ score $=0)$ or present $($ score $=1)$ and were clustered into four categories as following: central-based signs (Cs) (signs 1-6), MPSs (signs 7-10), cerebellar-based signs (CLs) (signs 11-12), and PR (signs 13). We defined the presence of Cs, MPS, CLs, and PR as the presence of at least one sign within those included in each of these clusters. Accordingly, subjects were divided into subjects without ISNAs (ISNA-) and with ISNAs (ISNA+) if at least one sign within the above clusters was present. The neurological examination of each participant was always performed by two neurologists blinded to the patient's history and neuroimaging. The interrater reliability assessed over time in random samples always showed excellent agreement with weighted Cohen's kappa ranging between 0.88 and $0.91(p<0.001)$.

\section{Functional and Neuropsychological Assessments}

The functional status of participants was assessed through the ADL and the IADL scales. Cognitive functions were assessed using an extensive neuropsychological battery as reported elsewhere, ${ }^{20,35}$ including the MMSE as test of global cognition and 12 tests to evaluate memory, attention, executive function, language, constructional ability, and visuospatial skill. Impaired cognitive domains were identified using a cut-off of 1.5 standard deviation $(\mathrm{SD})^{2}$ below the Italian normative data adjusted for age, sex, and education. ${ }^{36}$

\section{Carotid Ultrasonography and Imaging Assessments}

Intimal-medial thickness (IMT) and stenosis of internal carotid arteries (SICAs) were assessed as reported elsewhere. ${ }^{20}$ Participants had brain MRI on a $1.5 \mathrm{~T}$ scanner (GE Signa HDxt, Milwaukee, WI, USA). Details of the image acquisition protocol have been published previously. ${ }^{20}$ The $\mathrm{BCr}$ and the $\mathrm{LVBr}$ were calculated as reported elsewhere. ${ }^{20,35} \mathrm{WMH}$ and lacunes were assessed according to the published criteria. ${ }^{12}$ The Wahlund scale (range 0-3) ${ }^{37}$ was used to obtain the scores of WMH of the frontal, parieto-occipital, and temporal areas (WMH-SC), infratentorial (WMH-INF), basal ganglia (WMH-BG), and the WMH total score (WMH-T). To define the WMH status, a cut-off score $\geq 2$ in at least one of the above regions was used. WMH-PV were evaluated with the Fazekas scale (range 0-3), ${ }^{38}$ and a cut-off score $\geq 2$ was used. Lacunes were assessed topographically according to the Wahlund regions used to score $\mathrm{WMH}$ and categorized as lacunes-SC, lacunes-BG, lacunes-INF, and lacunes-T. A cut-off score $\geq 2$ in at least one of the Wahlund regions was used to define the status of lacunes. Subjects having WMH and/or lacunes with a score $\geq 2$ in at least one of the Wahlund scale topographical locations were categorized as SVD positive (SVD+), and those having WMH and/or lacunes with a score $\leq 1$ were categorized as SVD negative (SVD-).

\section{Statistical Analysis}

Descriptive statistics (percentages, mean and SD, median and interquartile range) were used to summarize data. Continuous variables were compared between subjects ISNAand ISNA+ by using one-way analysis of variance, and differences were tested with a post hoc $F$-test. Categorical variables were evaluated by contingency tables, and the hypotheses of independence were tested with $\chi^{2}$ test. Logistic ridge regression models ${ }^{39}$ were used to evaluate for each MCI type the risk of having ISNA co-varying for age, sex, years of education, and the variables found significant in the univariate analysis. In general, ridge regression method is the most applied solution for addressing problems of multicollinearity. ${ }^{40}$ It implies adding a small positive constant $(\lambda)$, i.e., the ridge parameter, to the main diagonal elements of the information matrix. The ridge parameter was selected using likelihood cross-validation. ${ }^{41}$ IMT, $\mathrm{BCr}$, and $\mathrm{LVBr}$ values were scaled to work on percentage of increments. All tests were two-tailed, and statistical significance was set at $p \leq 0.05$. Results are presented as odds ratios with $95 \%$ confidence interval. All analyses were performed using $\mathrm{R}$ statistical software (version 3.5.1; The R Foundation for Statistical Computing). 
Table 1: Demographic characteristics of MCI types

\begin{tabular}{|c|c|c|c|c|c|c|c|}
\hline & a-MCI & a-MCImd & na-MCI & na-MCImd & All MCI & \multirow{2}{*}{$\begin{array}{c}\text { Statistics: } \\
F \text { test or } X^{2} \text { test }\end{array}$} & \multirow[b]{2}{*}{$p$ Value } \\
\hline & $n=375(30.0)$ & $n=504(40.3)$ & $n=229(18.3)$ & $n=142(11.4)$ & $n=1.250$ & & \\
\hline \multicolumn{8}{|l|}{ Age classes } \\
\hline Adults & $127(33.9)$ & $101(20.0)$ & $68(29.7)$ & $23(16.2)$ & $319(25.5)$ & \multirow{4}{*}{36.20} & \multirow{4}{*}{$<0.001$} \\
\hline Elderly & 126 (33.6) & $205(40.7)$ & 79 (34.5) & $48(33.8)$ & 458 (36.6) & & \\
\hline Old & $106(28.3)$ & $171(33.9)$ & $72(31.4)$ & $59(41.5)$ & 408 (32.6) & & \\
\hline Oldest old & $16(4.3)$ & $27(5.4)$ & $10(4.4)$ & $12(8.5)$ & $65(5.2)$ & & \\
\hline \multicolumn{8}{|l|}{ Mean ages } \\
\hline Adults & $56.61 \pm 5.37$ & $57.78 \pm 5.00$ & $57.59 \pm 5.58$ & $57.52 \pm 5.66$ & $57.26 \pm 5.32$ & 1.05 & 0.370 \\
\hline Elderly & $69.63 \pm 2.79$ & $70.02 \pm 2.91$ & $70.03 \pm 2.64$ & $70.21 \pm 2.55$ & $69.93 \pm 2.79$ & 0.76 & 0.517 \\
\hline Old & $78.16 \pm 2.46$ & $78.10 \pm 2.70$ & $78.19 \pm 2.38$ & $78.64 \pm 2.72$ & $78.21 \pm 2.59$ & 0.67 & 0.571 \\
\hline Oldest old & $87.12 \pm 2.45$ & $87.04 \pm 2.05$ & $87.70 \pm 2.00$ & $87.50 \pm 3.14$ & $87.25 \pm 2.39$ & 0.24 & 0.869 \\
\hline
\end{tabular}

MCI = mild cognitive impairment; a-MCI = amnestic mild cognitive impairment single domain; a-MCImd = amnestic mild cognitive impairment multiple domain; na-MCI = nonamnestic mild cognitive impairment single domain; na-MCImd = nonamnestic mild cognitive impairment multiple domain.

Data presented are number $(\%)$ for categorical and mean \pm SD for continuous data.

Tests $F$ and $X^{2}$ were performed across four MCI types.

Bold values indicate significance at $p \leq 0.05$.

\section{RESULTS}

The demographic characteristics of the MCI types are shown in Table 1. In almost all MCI types, the majority of subjects were elderly followed by old, adult, and oldest-old individuals. The MCI types single domain were more common among the adults, while those multiple domain were more common within the elderly, old, and oldest-old participants. In each age class, the mean age did not vary significantly among the various MCI types. Since the oldestold subjects were few, subsequent analysis was conducted pooling the old and oldest-old classes in the class of old-oldest old.

Within the sample, $175(14.0 \%)$ subjects did not show any of the selected ISNA, while $1075(86.0 \%)$ presented at least one ISNA (Table 2). Overall, subjects ISNA- were more common among the MCI types single domain, and subjects ISNA+ were more common among those multiple domain. PRs were the most frequent ISNA, followed by ISNA central-based and MPSs, while ISNA cerebellar-based were the rarest. PRs were exhibited by 864 subjects $(69.1 \%)$ of the sample and were more common among the MCI types multiple domain than those single domain. In all MCI types, snout reflex was the most common PR followed by glabellar tap and palmomental reflex, while grasping and sucking reflexes were the rarest. Snout and palmomental reflexes were more common among the MCI types multiple domain than those single domain, while glabellar tap was more common among the amnestic MCI types than the nonamnestic types. The mean number of PRs was greater among the amnestic MCI types than the nonamnestic types. Central-based signs were exhibited by 645 subjects $(51.6 \%)$ of the sample. Subjects with Cs were more common among the nonamnestic MCI types than the amnestic types. In all MCI types, reflex asymmetry was the most common Cs, followed by bilateral hyperreflexia, central facial weakness, mixed rigidity, slurred speech, and dysphagia. Reflex asymmetry, bilateral hyperreflexia, and central facial weakness were more common among the nonamnestic MCI types than the amnestic types, while the frequency of the other Cs did not vary among the four MCI types. The mean number of Cs was greater among the nonamnestic MCI types than the amnestic types. MPSs were found in 46.2\% $(n=578)$ of the sample. In all MCI types, bradykinesia was the most common MPS, followed by gait/balance/axial dysfunction, and tremor, while rigidity was the rarest. Individual MPSs were more common among the MCI types multiple domain than the MCI single domain. The mean number of MPS was greater in the former than in the latter. CLs were the rarest ISNA encountered. Dysmetria was the most common CLs, and the atactic type gait was the rarest. The frequency of dysmetria did not vary among the four MCI types, while the atactic type gait was more common among the a-MCImd than the other MCI types. The mean number of CLs did not vary among the MCI types.

ISNA increased with age reaching a peak in the old-oldest old individuals (Table 3). Among the adults, 210 subjects $(65.8 \%)$ were ISNA+ and 109 subjects $(34.2 \%)$ were ISNA-. PRs were the most frequent ISNA followed by Cs, MPS, and CLs categories. PR, Cs, and MPS were more common among the MCI types multiple domain than those single domain, while CLs did not vary in the four MCI types. The mean number of ISNA was greater in the former than in the latter. Within the elderly, 405 subjects $(88.4 \%)$ were ISNA+ and 53 subjects $(11.6 \%)$ were ISNA-. The frequency of subjects ISNA+ did not vary among the four MCI types. PRs were the most frequent ISNA followed by Cs, MPS, and CLs categories. PRs were almost equally distributed in the four MCI types, MPS and CLs were more common among the MCI types multiple domain, and $\mathrm{Cs}$ were more common among the nonamnestic MCI types. The mean number of ISNA was greater in the nonamnestic MCI types than in the amnestic 
Table 2: Frequency of ISNA selected in MCI types

\begin{tabular}{|c|c|c|c|c|c|c|c|}
\hline & a-MCI & a-MCImd & na-MCI & na-MCImd & All MCI & \multirow{2}{*}{$\begin{array}{c}\text { Statistics: } \\
F \text { test or } X^{2} \text { test }\end{array}$} & \multirow[b]{2}{*}{$p$ Value } \\
\hline & $n=375(30.0)$ & $n=504(40.3)$ & $n=229(18.3)$ & $n=142(11.4)$ & $n=1.250$ & & \\
\hline $\begin{array}{l}\text { Subjects without } \\
\text { ISNA }\end{array}$ & $76(20.3)$ & $47(9.3)$ & $41(17.9)$ & $11(7.8)$ & $175(14.0)$ & \multirow[t]{2}{*}{30.13} & \multirow{2}{*}{$<0.001$} \\
\hline Subjects with ISNA & $299(79.7)$ & $457(90.7)$ & $188(82.1)$ & $131(92.2)$ & $1.075(86.0)$ & & \\
\hline \multicolumn{8}{|c|}{ Primitive Reflexes (PRs) } \\
\hline $\begin{array}{c}\mathrm{N}^{\circ} \text { of subjects } \\
\text { without } \mathrm{PR}\end{array}$ & $123(32.8)$ & $132(26.2)$ & $89(38.9)$ & $42(29.6)$ & $386(30.9)$ & \multirow{2}{*}{12.79} & \multirow{2}{*}{0.005} \\
\hline $\begin{array}{l}\mathrm{N}^{\circ} \text { of subjects } \\
\text { with PR }\end{array}$ & $252(67.2)$ & $372(73.8)$ & $140(61.1)$ & $100(70.4)$ & $864(69.1)$ & & \\
\hline Sucking reflex & $0(0.0)$ & $1(0.2)$ & $1(0.4)$ & $0(0.0)$ & $2(0.2)$ & 1.97 & 0.578 \\
\hline Grasping reflex & $2(0.5)$ & $4(0.8)$ & $1(0.4)$ & $0(0.0)$ & $7(0.6)$ & 1.36 & 0.715 \\
\hline Palmomental reflex & $78(20.8)$ & $125(24.8)$ & $40(17.5)$ & $41(28.9)$ & $284(22.7)$ & 8.69 & 0.034 \\
\hline Glabellar tap & $172(45.9)$ & $232(46.0)$ & $86(37.6)$ & $43(30.3)$ & $533(42.6)$ & 15.26 & 0.002 \\
\hline Snout reflex & $202(53.9)$ & $314(62.3)$ & $110(48.0)$ & $84(59.2)$ & $710(56.8)$ & 15.02 & 0.002 \\
\hline Mean number of PR & $1.21 \pm 1.04$ & $1.34 \pm 1.02$ & $1.04 \pm 1.01$ & $1.18 \pm 0.98$ & $1.23 \pm 1.02$ & 4.82 & $<0.001$ \\
\hline \multicolumn{8}{|l|}{ Central signs (Cs) } \\
\hline $\begin{array}{c}\mathrm{N}^{\circ} \text { of subjects } \\
\text { without } \mathrm{Cs}\end{array}$ & $214(57.1)$ & $266(52.8)$ & $87(38.0)$ & $38(26.8)$ & $605(48.4)$ & \multirow{2}{*}{51.71} & \multirow{2}{*}{$<0.001$} \\
\hline $\begin{array}{l}\mathrm{N}^{\circ} \text { of subjects } \\
\text { with Cs }\end{array}$ & $161(42.9)$ & $238(47.2)$ & $142(62.0)$ & $104(73.2)$ & $645(51.6)$ & & \\
\hline Dysphagia & $4(1.1)$ & $7(1.4)$ & $2(0.9)$ & $3(2.1)$ & $16(1.3)$ & 1.26 & 0.738 \\
\hline Slurred speech & $5(1.3)$ & $12(2.4)$ & $5(2.2)$ & $4(2.8)$ & $26(2.1)$ & 1.64 & 0.650 \\
\hline Mixed rigidity & $11(2.9)$ & $31(6.2)$ & $8(3.5)$ & $10(7.0)$ & $60(4.8)$ & 7.29 & 0.063 \\
\hline $\begin{array}{c}\text { Central facial } \\
\text { weakness }\end{array}$ & $56(14.9)$ & $92(18.3)$ & $95(41.5)$ & $90(63.4)$ & $333(26.6)$ & 168.34 & $<0.001$ \\
\hline $\begin{array}{l}\text { Bilateral } \\
\text { hyperreflexia }\end{array}$ & $89(23.7)$ & 144 (28.6) & $63(27.5)$ & $65(45.8)$ & $361(28.9)$ & 22.80 & $<0.001$ \\
\hline Reflex asimmetry & $103(27.5)$ & $137(27.2)$ & $101(44.1)$ & $62(43.7)$ & $403(32.2)$ & 33.05 & $<0.001$ \\
\hline Mean number of Cs & $0.71 \pm 1.00$ & $0.84 \pm 1.06$ & $1.20 \pm 1.14$ & $1.65 \pm 1.22$ & $0.96 \pm 1.12$ & 31.59 & $<0.001$ \\
\hline \multicolumn{8}{|c|}{ Mild Parkinsonian signs (MPSs) } \\
\hline $\begin{array}{l}\mathrm{N}^{\circ} \text { of subjects } \\
\text { without MPS }\end{array}$ & $244(65.1)$ & $230(45.6)$ & $141(61.6)$ & $57(40.1)$ & $672(53.8)$ & \multirow{2}{*}{49.89} & \multirow{2}{*}{$<0.001$} \\
\hline $\begin{array}{c}\mathrm{N}^{\circ} \text { of subjects } \\
\text { with MPS }\end{array}$ & $131(34.9)$ & $274(54.4)$ & $88(38.4)$ & $85(59.9)$ & $578(46.2)$ & & \\
\hline Rigidity & $23(6.1)$ & $52(10.3)$ & $11(4.8)$ & $15(10.6)$ & $101(8.1)$ & 9.80 & 0.002 \\
\hline Tremor & $29(7.7)$ & $36(7.1)$ & $21(9.2)$ & $24(16.9)$ & $110(8.8)$ & 13.91 & 0.003 \\
\hline $\begin{array}{l}\text { Gait/balance/axial } \\
\text { dysfunction }\end{array}$ & $63(16.8)$ & $155(30.8)$ & $36(15.7)$ & $44(31.0)$ & $298(23.8)$ & 35.81 & $<0.001$ \\
\hline Bradykinesia & $99(26.4)$ & $230(45.6)$ & $65(28.4)$ & $70(49.3)$ & $464(37.1)$ & 50.63 & $<0.001$ \\
\hline $\begin{array}{l}\text { Mean number } \\
\text { of MPS }\end{array}$ & $0.57 \pm 0.88$ & $0.94 \pm 1.03$ & $0.58 \pm 0.86$ & $1.08 \pm 1.09$ & $0.78 \pm 0.99$ & 18.09 & $<0.001$ \\
\hline \multicolumn{8}{|l|}{ Cerebellar signs (CLs) } \\
\hline $\begin{array}{r}\mathrm{N}^{\circ} \text { of subjects } \\
\text { without CLs }\end{array}$ & $359(95.7)$ & $469(93.1)$ & $214(93.4)$ & $131(92.2)$ & $1173(93.8)$ & \multirow{2}{*}{3.54} & \multirow{2}{*}{0.316} \\
\hline $\begin{array}{l}\mathrm{N}^{\circ} \text { of subjects with } \\
\mathrm{CLs}\end{array}$ & $16(4.3)$ & $35(6.9)$ & $15(6.6)$ & $11(7.8)$ & $77(6.2)$ & & \\
\hline Atactic type gait & $0(0.0)$ & $9(1.8)$ & $6(2.6)$ & $2(1.4)$ & $17(1.4)$ & 8.56 & 0.036 \\
\hline
\end{tabular}


Table 2: (Continued)

\begin{tabular}{|c|c|c|c|c|c|c|c|}
\hline & a-MCI & a-MCImd & na-MCI & na-MCImd & All MCI & Statistics: & \\
\hline & $n=375(30.0)$ & $n=504(40.3)$ & $n=229$ & $n=142(11.4)$ & $n=1.250$ & $F$ test or $X^{2}$ test & $p$ Value \\
\hline Dysmetria & $16(4.3)$ & $29(5.8)$ & $11(4.8)$ & $10(7.0)$ & $66(5.3)$ & 1.98 & 0.576 \\
\hline $\begin{array}{l}\text { Mean number of } \\
\text { CLs }\end{array}$ & $0.04 \pm 0.20$ & $0.08 \pm 0.29$ & $0.07 \pm 0.29$ & $0.08 \pm 0.30$ & $0.07 \pm 0.27$ & 1.46 & 0.225 \\
\hline
\end{tabular}

ISNA = isolated, subtle neurological abnormalities; $\mathrm{MCI}=$ mild cognitive impairment; a-MCI = amnestic mild cognitive impairment single domain; a-MCImd = amnestic mild cognitive impairment multiple domain; na-MCI = nonamnestic mild cognitive impairment single domain; na-MCImd = nonamnestic mild cognitive impairment multiple domain.

Data presented are number (\%) for categorical and mean \pm SD for continuous data.

Tests $F$ and $X^{2}$ were performed across four MCI types.

Bold values indicate significance at $p \leq 0.05$.

types. Among the old-oldest old subjects, 461 individuals $(97.5 \%)$ presented at least one ISNA and 12 individuals only (2.5\%) were ISNA-. CLs and MPS did not vary among the four MCI types. Cs were significantly more common among the nonamnestic MCI types, while PRs were significantly more common among the amnestic MCI type. The mean number of ISNA was significantly greater in the na-MCImd type than in the other MCI types. The co-occurrence of multiple ISNAs increased with age in all MCI types.

Baseline characteristics of MCI types ISNA+ and ISNA- are shown in Table 4. In all MCI types, no difference was found in the distribution of female and male among the two ISNA groups. In all MCI types, the mean age of female was greater in subjects ISNA+ than in subjects ISNA-, while the mean age of male was greater in subjects ISNA+ than in subjects ISNA- in the a-MCI only. Level of education did not vary among the ISNA groups in MCI types single domain and in a-MCImd type, while in the na-MCImd type, subjects ISNA+ were less educated than subjects ISNA-. The ADL scores were worse in the MCI types single domain ISNA+ only, and the IADL scores were worse in the MCI types single domain and aMCImd ISNA+. In the na-MCImd type, ADL and IADL scores did not vary among the two ISNA groups. Out of the VRFs evaluated, arterial hypertension only was significantly more common among subjects ISNA+ than subjects ISNA- with the na-MCImd type, while no difference was found in the distribution of VRFs among the two ISNA groups of the other MCI types. However, in a-MCI and na-MCImd, the VRF summary score was greater in subjects ISNA+ than those ISNA-. No difference was found in the frequency of the VD evaluated among subjects ISNA+ and ISNA - of almost all MCI types, with the exception of history of TIA that was significantly more common among the subjects a-MCI ISNA+. The VD summary score was greater in subjects ISNA+ than in those ISNA- in the a-MCI only. In the a-MCI type, APOE $€ 4$ carriers were significantly more common in subjects ISNA+ than in subjects ISNA- and APOE $€ 4$ noncarriers were significantly more common in subjects ISNA- than in subjects ISNA+. The distribution of APOE $€ 4$ carriers and noncarriers did not differ in the two ISNA groups of the other MCI types.

Neuropsychological performances of MCI types ISNA+ and ISNA- are summarized in Table 5. The MMSE score was above the cut-off level in all MCI types, but subjects a-MCI ISNA+ performed significantly less than subjects ISNA-. As expected, a worse performance on memory task was exhibited by the amnestic MCI types ISNA+ and ISNA-. In subjects with a-MCI, the nonmemory domains were not impaired, but subjects ISNA+ performed significantly less than subjects ISNA- in attention, executive function, and language. In subjects a-MCImd ISNA+ and ISNA-, the nonmemory domains were impaired and subjects ISNA+ performed significantly worse than subjects ISNA- in tests evaluating language. In the nonamnestic MCI types, no significant difference was found in the performance of nonmemory domains among subjects ISNA+ and ISNA-, although a trend of worse performance of subjects ISNA+ in almost all cognitive domains was evident.

Carotid ultrasonography and imaging findings in the MCI types ISNA+ and ISNA- are reported in Table 6. In all MCI types, the frequency of IMT was significantly higher in subjects ISNA+ than subjects ISNA-, while the frequency of SICA did not differ between the two ISNA groups. In a-MCI, na-MCI, and na-MCImd, WMH-SC, WMH-T, and WMH-PV were significantly higher in subjects ISNA+ than subjects ISNA-, while in a-MCImd, WMH-BG only were significantly higher in subjects ISNA+. Lacunes-BG and lacunes-T were significantly higher in MCI types single domain ISNA+, and lacunes-T were significantly higher in na-MCImd ISNA+. In a-MCI, na-MCI, and na-MCImd, SVD+ was more common in subjects ISNA+ than ISNA-, while SVD- was more common among the subjects ISNA - than ISNA+. In a-MCImd, the distribution of subjects SVD+ and SVD- did not differ among the two ISNA groups. $\mathrm{BCr}$ was significantly higher in all MCI types ISNA+ with the exception of a-MCImd type. LVBr was significantly higher in the MCI types single domain ISNA+, while no difference among the ISNA groups was found in the MCI types multiple domains.

To assess the effects of the variables evaluated on the estimated probability of having at least one ISNA, logistic ridge regression analysis was carried out in each MCI type (Table 7). Age resulted associated with a-MCI type only. For each year of age increase, the odds of having at least one ISNA went up about $3 \%$. Being female increased by $7.7 \%$ the probability of having at least one ISNA in the a-MCI type only. Education and VRF summary score did not influence the probability of having at least one ISNA in any of the MCI types. VD summary score increased the probability of having at least one ISNA in a-MCI $(18.1 \%)$, na-MCI (11.1\%), and na-MCImd (4.5\%). Being carrier of the APOE $€ 4$ allele increased by $52.7 \%, 16.5 \%$, and $5.1 \%$ the probability of having at least one ISNA in a-MCI, a-MCImd, and na-MCImd, respectively. At the increase of a single percentage point of the IMT, the probability of having at least one ISNA in a-MCI, a-MCImd, na-MCI, and na-MCImd went up by $52.7 \%, 36.9 \%$, $14.8 \%$, and $16.3 \%$, respectively. The presence of WMH-PV 
Table 3: Frequency of ISNA categories in MCI types according to age classes

\begin{tabular}{|c|c|c|c|c|c|c|c|}
\hline & a-MCI & a-MCImd & na-MCI & na-MCImd & All MCI & \multirow{2}{*}{$\begin{array}{c}\text { Statistics: } \\
F \text { test or } X^{2_{2}} \text { test }\end{array}$} & \multirow[b]{2}{*}{$p$ Value } \\
\hline & $n=375(30.0)$ & $n=504(40.3)$ & $n=229(18.3)$ & $n=142(11.4)$ & $n=1.250$ & & \\
\hline \multicolumn{8}{|l|}{ Age classes } \\
\hline Adults & $127(33.9)$ & $101(20.0)$ & $68(29.7)$ & $23(16.2)$ & $319(25.5)$ & & \\
\hline $\begin{array}{l}\text { Subjects without } \\
\text { ISNA }\end{array}$ & $57(44.9)$ & $20(19.8)$ & $27(39.7)$ & $5(21.7)$ & $109(34.2)$ & \multirow{2}{*}{18.25} & \multirow{2}{*}{$<0.001$} \\
\hline $\begin{array}{l}\text { Subjects with } \\
\text { ISNA }\end{array}$ & $70(55.1)$ & $81(80.2)$ & $41(60.3)$ & $18(78.3)$ & $210(65.8)$ & & \\
\hline \multicolumn{8}{|l|}{ ISNA categories } \\
\hline $\begin{array}{l}\text { Primitive } \\
\text { reflexes }\end{array}$ & $49(38.6)$ & $63(62.4)$ & $20(29.4)$ & $10(43.5)$ & $142(44.5)$ & 21.15 & $<0.001$ \\
\hline Central signs & $32(25.2)$ & 42 (41.6) & $26(38.2)$ & $13(56.5)$ & $113(35.4)$ & 12.19 & 0.007 \\
\hline $\begin{array}{l}\text { Mild } \\
\text { parkinsonian } \\
\text { signs }\end{array}$ & $15(11.8)$ & $35(34.7)$ & $9(13.2)$ & $7(30.4)$ & $66(20.7)$ & 21.74 & $<0.001$ \\
\hline Cerebellar signs & $4(3.2)$ & $5(5.0)$ & $1(1.5)$ & $1(4.4)$ & $11(3.5)$ & 1.57 & 0.665 \\
\hline $\begin{array}{c}\text { Mean number } \\
\text { of ISNA }\end{array}$ & $1.13 \pm 1.46$ & $2.43 \pm 1.87$ & $1.26 \pm 1.39$ & $2.52 \pm 2.13$ & $1.68 \pm 1.75$ & 14.82 & $<0.001$ \\
\hline Elderly & $126(33.6)$ & $205(40.7)$ & $79(34.5)$ & $48(33.8)$ & $458(29.5)$ & & \\
\hline $\begin{array}{l}\text { Subjects without } \\
\text { ISNA }\end{array}$ & $19(15.1)$ & $19(9.3)$ & $12(15.2)$ & $3(6.3)$ & $53(11.6)$ & \multirow{2}{*}{4.92} & \multirow{2}{*}{0.178} \\
\hline $\begin{array}{l}\text { Subjects with } \\
\text { ISNA }\end{array}$ & $107(84.9)$ & $186(90.7)$ & $67(84.8)$ & $45(93.7)$ & $405(88.4)$ & & \\
\hline \multicolumn{8}{|l|}{ ISNA categories } \\
\hline $\begin{array}{l}\text { Primitive } \\
\text { reflexes }\end{array}$ & $82(65.1)$ & $138(67.3)$ & $54(68.4)$ & $32(66.7)$ & $306(66.8)$ & 0.28 & 0.964 \\
\hline Central signs & $53(42.1)$ & $104(50.7)$ & $50(63.3)$ & $33(68.7)$ & $240(52.4)$ & 14.53 & 0.002 \\
\hline $\begin{array}{l}\text { Mild } \\
\text { parkinsonian } \\
\text { signs }\end{array}$ & $44(34.9)$ & $111(54.2)$ & $29(36.7)$ & $24(50.0)$ & $208(45.4)$ & 14.73 & 0.002 \\
\hline Cerebellar signs & $1(0.8)$ & $17(8.3)$ & $6(7.6)$ & $5(10.4)$ & $29(6.3)$ & 9.41 & 0.024 \\
\hline $\begin{array}{c}\text { Mean number } \\
\text { of ISNA }\end{array}$ & $2.17 \pm 1.53$ & $2.89 \pm 1.84$ & $2.97 \pm 2.03$ & $3.29 \pm 2.12$ & $2.75 \pm 1.86$ & 7.53 & $<0.001$ \\
\hline Old-oldest old & $122(32.5)$ & $198(39.3)$ & $82(35.8)$ & $71(50.0)$ & $473(37.8)$ & & \\
\hline $\begin{array}{l}\text { Subjects without } \\
\text { ISNA }\end{array}$ & $0(0.0)$ & $8(4.0)$ & $2(2.4)$ & $2(2.8)$ & $12(2.5)$ & \multirow{2}{*}{5.01} & \multirow{2}{*}{0.171} \\
\hline $\begin{array}{l}\text { Subjects with } \\
\text { ISNA }\end{array}$ & $122(100.0)$ & $190(96.0)$ & $80(97.6)$ & $69(97.2)$ & $461(97.5)$ & & \\
\hline \multicolumn{8}{|l|}{ ISNA categories } \\
\hline $\begin{array}{c}\text { Primitive } \\
\text { reflexes }\end{array}$ & $121(99.2)$ & $171(86.4)$ & $66(80.5)$ & $58(75.3)$ & $416(87.9)$ & 21.92 & $<0.001$ \\
\hline Central signs & $76(62.3)$ & $92(46.5)$ & $66(80.5)$ & $58(75.3)$ & $292(61.7)$ & 43.74 & $<0.001$ \\
\hline $\begin{array}{l}\text { Mild } \\
\text { parkinsonian } \\
\text { signs } \\
\end{array}$ & $72(59.0)$ & $128(64.6)$ & $50(61.0)$ & $54(70.1)$ & $304(64.3)$ & 6.16 & 0.104 \\
\hline Cerebellar signs & $11(9.0)$ & $13(6.6)$ & $8(9.8)$ & $5(6.5)$ & $37(7.8)$ & 1.16 & 0.763 \\
\hline $\begin{array}{l}\text { Mean number } \\
\text { of ISNA }\end{array}$ & $4.37 \pm 1.97$ & $3.90 \pm 1.93$ & $4.13 \pm 1.95$ & $4.97 \pm 2.16$ & $4.22 \pm 2.01$ & 5.16 & 0.002 \\
\hline
\end{tabular}

ISNA = isolated, subtle neurological abnormalities; $\mathrm{MCI}=$ mild cognitive impairment; a-MCI = amnestic mild cognitive impairment single domain; a-MCImd = amnestic mild cognitive impairment multiple domain; na-MCI = nonamnestic mild cognitive impairment single domain; na-MCImd = nonamnestic mild cognitive impairment multiple domain; MPSs = mild parkinsonian signs; Cs = central-based signs; CLs = cerebellar-based signs.

Data presented are number $(\%)$ for categorical and mean \pm SD for continuous data.

Tests $F$ and $X^{2}$ were performed across four MCI types.

Bold values indicate significance at $p \leq 0.05$. 
Table 4: Baseline characteristics of MCI types with at least one ISNA (ISNA+) and without ISNA (ISNA-)

\begin{tabular}{|c|c|c|c|c|c|c|c|c|c|c|c|c|}
\hline & \multicolumn{2}{|c|}{ a-MCI $(n=375)$} & \multirow[b]{3}{*}{$p$ value } & \multicolumn{2}{|c|}{ a-MCImd $(n=504)$} & \multirow[b]{3}{*}{$p$ value } & \multicolumn{2}{|c|}{ na-MCI $(n=229)$} & \multirow[b]{3}{*}{$p$ value } & \multicolumn{2}{|c|}{ na-MCImd $(n=142)$} & \multirow[b]{3}{*}{$p$ value } \\
\hline & \multirow{2}{*}{$\begin{array}{c}\text { ISNA+ } \\
n=299 \\
(79.7) \\
\end{array}$} & \multirow{2}{*}{\begin{tabular}{|c|} 
ISNA- \\
$n=76(20.3)$ \\
\end{tabular}} & & \multirow{2}{*}{$\begin{array}{c}\text { ISNA+ } \\
n=457 \\
(90.7)\end{array}$} & \multirow{2}{*}{\begin{tabular}{|c|} 
ISNA- \\
$n=47(9.3)$ \\
\end{tabular}} & & \multirow{2}{*}{$\begin{array}{c}\text { ISNA+ } \\
n=188 \\
(82.1)\end{array}$} & \multirow{2}{*}{\begin{tabular}{|c|} 
ISNA- \\
$n=41(17.9)$ \\
\end{tabular}} & & \multirow{2}{*}{$\begin{array}{c}\text { ISNA+ } \\
n=132 \\
(93.0)\end{array}$} & \multirow{2}{*}{\begin{tabular}{|c|} 
ISNA- \\
$n=10(7.0)$ \\
\end{tabular}} & \\
\hline & & & & & & & & & & & & \\
\hline \multicolumn{13}{|l|}{ Sex } \\
\hline Female & $161(53.9)$ & $48(63.2)$ & \multirow{2}{*}{0.184} & $260(56.9)$ & $29(61.7)$ & \multirow{2}{*}{0.631} & $125(66.5)$ & $28(68.3)$ & \multirow{2}{*}{0.969} & $54(40.9)$ & $7(70.0)$ & \multirow{2}{*}{0.731} \\
\hline Male & $138(46.1)$ & $28(36.8)$ & & $197(43.1)$ & $18(38.3)$ & & $63(33.5)$ & $13(31.7)$ & & $78(59.1)$ & $3(30.0)$ & \\
\hline Female (mean age, years) & $70.20 \pm 9.10$ & $59.44 \pm 8.46$ & $<0.001$ & $72.08 \pm 7.85$ & $64.97 \pm 9.21$ & $<0.001$ & $71.54 \pm 9.85$ & $62.4 \pm 7.59$ & $<0.001$ & $73.18 \pm 8.69$ & $61.71 \pm 12.30$ & 0.002 \\
\hline Male (mean age, years) & $71.52 \pm 9.44$ & $57.71 \pm 6.51$ & $<0.001$ & $71.35 \pm 9.47$ & $67.50 \pm 9.33$ & 0.100 & $70.89 \pm 8.34$ & $60.33 \pm 7.06$ & $<0.001$ & $74.80 \pm 8.51$ & $68.00 \pm 8.54$ & 0.184 \\
\hline Education (years) & $7.88 \pm 4.64$ & $8.53 \pm 5.37$ & 0.3297 & $6.23 \pm 4.49$ & $7.04 \pm 4.16$ & 0.237 & $6.40 \pm 4.06$ & $6.33 \pm 3.37$ & 0.793 & $5.83 \pm 3.69$ & $7.60 \pm 4.67$ & $<0.001$ \\
\hline \multicolumn{13}{|l|}{ Functional assessment } \\
\hline ADL (f.l.) & $0.32 \pm 0.58$ & $0.16 \pm 0.40$ & 0.021 & $0.52 \pm 0.85$ & $0.40 \pm 0.61$ & 0.351 & $0.37 \pm 0.69$ & $0.15 \pm 0.42$ & 0.046 & $0.42 \pm 0.69$ & $0.20 \pm 0.42$ & 0.313 \\
\hline IADL (f.l.) & $0.6 \pm 1.14$ & $0.24 \pm 0.61$ & 0.001 & $1.20 \pm 1.44$ & $0.77 \pm 1.16$ & 0.044 & $0.66 \pm 1.27$ & $0.17 \pm 0.38$ & 0.014 & $0.91 \pm 1.18$ & $0.20 \pm 0.42$ & 0.062 \\
\hline \multicolumn{13}{|l|}{ Vascular risk factors } \\
\hline Never/former smoking & $229(76.6)$ & $55(72.4)$ & \multirow{2}{*}{0.538} & $342(75.3)$ & $41(87.2)$ & \multirow{2}{*}{0.099} & $151(80.3)$ & $29(70.7)$ & \multirow{2}{*}{0.252} & $109(82.6)$ & $9(90.0)$ & \multirow{2}{*}{0.868} \\
\hline Current smoking & $70(23.4)$ & $21(27.6)$ & & $112(24.7)$ & $6(12.7)$ & & 37 (19.7) & $12(29.3)$ & & $23(17.4)$ & $1(10.0)$ & \\
\hline Arterial hypertension & $209(69.9)$ & $44(57.9)$ & 0.063 & $348(76.3)$ & $32(66.7)$ & 0.296 & $141(75.0)$ & $29(70.7)$ & 0.712 & $111(84.1)$ & $5(50.0)$ & 0.024 \\
\hline Diabetes mellitus* & $72(26.4)$ & $17(26.2)$ & 1.000 & $116(27.9)$ & $17(36.2)$ & 0.259 & $56(30.9)$ & $7(18.4)$ & 0.176 & $40(33.3)$ & $1(11.1)$ & 0.313 \\
\hline Hypercholesterolemia* & $128(43.0)$ & $26(33.8)$ & 0.183 & $179(39.2)$ & $21(42.6)$ & 0.768 & $77(40.9)$ & $17(41.5)$ & 1.000 & $50(37.9)$ & $1(10.0)$ & 0.153 \\
\hline Hypertriglyceridemia* & $68(24.1)$ & $12(16.9)$ & 0.255 & $99(22.7)$ & $16(34.0)$ & 0.098 & $52(28.3)$ & $11(28.9)$ & 1.000 & 34 (26.6) & $1(11.1)$ & 0.527 \\
\hline Obesity* & $102(34.8)$ & $23(31.1)$ & 0.640 & $171(37.8)$ & $13(27.7)$ & 0.271 & $84(44.9)$ & $18(43.9)$ & 1.000 & $62(47.0)$ & $1(10.0)$ & 0.053 \\
\hline COPD & $29(9.7)$ & $4(5.2)$ & 0.304 & $51(11.2)$ & $1(2.1)$ & 0.091 & $18(9.6)$ & $1(2.4)$ & 0.235 & $8(6.1)$ & $1(10.0)$ & 1.000 \\
\hline VRF summary score & $2.03 \pm 1.27$ & $1.6 \pm 1.27$ & 0.002 & $2.11 \pm 1.26$ & $2.11 \pm 1.13$ & 0.987 & $2.28 \pm 1.24$ & $2.02 \pm 1.15$ & 0.232 & $2.31 \pm 1.22$ & $1.00 \pm 0.82$ & 0.001 \\
\hline
\end{tabular}




\begin{tabular}{|c|c|c|c|c|c|c|c|c|c|c|c|c|}
\hline Ischaemic hearth diseases & $37(12.4)$ & $4(5.2)$ & 0.108 & $61(13.3)$ & $7(14.9)$ & 0.943 & $22(11.7)$ & $1(2.4)$ & 0.133 & $18(13.6)$ & $1(10.0)$ & 1.00 \\
\hline Cardiac valvulopathies & $20(33.9)$ & $1(8.3)$ & 0.155 & $24(25.0)$ & $3(25.0)$ & 1.000 & $12(29.3)$ & $0(0.0)$ & 0.301 & $8(44.4)$ & $0(0.0)$ & 1.00 \\
\hline Atrial fibrillation & $23(7.7)$ & $2(2.6)$ & 0.177 & $35(7.7)$ & $0(0.0)$ & 0.095 & $11(5.9)$ & $1(2.4)$ & 0.616 & $6(4.6)$ & $0(0.0)$ & 1.00 \\
\hline Lower limb arteriopathy & $7(2.4)$ & $3(3.9)$ & 0.723 & $17(3.2)$ & $2(4.3)$ & 1.000 & $3(1.6)$ & $0(0.0)$ & 0.955 & $4(3.0)$ & $0(0.0)$ & 1.00 \\
\hline History of TIA & $28(9.4)$ & $0(0.0)$ & 0.011 & $30(6.6)$ & $6(12.8)$ & 0.204 & $11(5.9)$ & $5(12.2)$ & 0.269 & $12(9.1)$ & $0(0.0)$ & 0.684 \\
\hline VD summary score & $0.38 \pm 0.66$ & $0.13 \pm 0.38$ & 0.001 & $0.37 \pm 0.63$ & $0.38 \pm 0.71$ & 0.857 & $0.31 \pm 0.56$ & $0.17 \pm 0.38$ & 0.120 & $0.36 \pm 0.62$ & $0.10 \pm 0.32$ & 0.187 \\
\hline \multicolumn{13}{|l|}{ APOE } \\
\hline APOE $€ 4$ carriers & $262(87.6)$ & $42(55.3)$ & \multirow{2}{*}{$<0.001$} & $412(90.4)$ & $40(85.1)$ & \multirow{2}{*}{0.379} & $106(56.4)$ & $21(51.2)$ & \multirow{2}{*}{0.668} & $95(72.0)$ & $5(50.0)$ & \multirow{2}{*}{0.268} \\
\hline APOE $€ 4$ noncarriers & $37(12.4)$ & $34(44.7)$ & & $44(9.6)$ & $7(14.9)$ & & $82(43.6)$ & $20(48.8)$ & & $37(28.0)$ & $5(50.0)$ & \\
\hline
\end{tabular}

MCI = mild cognitive impairment; ISNA = isolated, subtle neurological abnormalities; a-MCI = amnestic mild cognitive impairment single domain; a-MCImd = amnestic mild cognitive impairmen multiple domain; na-MCI = nonamnestic mild cognitive impairment single domain; na-MCImd = nonamnestic mild cognitive impairment multiple domain; ADL (f.l.) = activities of daily living (functions lost); IADL (f.l.) = instrumental activities of daily living (functions lost); COPD = chronic obstructive pulmonary disease; TIA = transient ischemic attacks; APOE = apolipoprotein E. Data presented are number $(\%)$ for categorical and mean \pm SD for continuous data.

Tests $F$ and $X^{2}$ were performed across the subjects ISNA+ and ISNA- of each MCI type.

Bold values indicate significance at $p \leq 0.05$.

*Number and percentage of missing data:Diabetes mellitus: a-MCI ISNA+ = 25 (8.0\%); a-MCI ISNA- = 12 (16.0\%); a-MCImd ISNA+ = 40 (9.0\%); a-MCImd ISNA- = 1 (2.0); na-MCI ISNA $+=7(4.0 \%)$; na-MCI ISNA- = $3(8.0 \%)$; na-MCImd ISNA+ = $12(9.0 \%)$; na-MCImd ISNA- = $1(10.0 \%)$.

Hypertriglyceridemia: a-MCI ISNA+ = 16 (5.0\%); a-MCI ISNA- = $6(8.0 \%)$; a-MCImd ISNA+ = 20 (4.0\%); a-MCImd ISNA- = $1(2.0)$; na-MCI ISNA+ = 4 (2.0\%); na-MCI ISNA- = 3 (8.0\%); na-MCImd ISNA $+=4(3.0 \%)$; na-MCImd ISNA- = $1(10.0 \%)$.

Obesity (Body Mass Index): a-MCI ISNA+ = 5 (2.0\%); a-MCI ISNA- = 3 (4.0\%); a-MCImd ISNA+= 3 (1.0\%); a-MCImd ISNA- = 1 (2.0); na-MCI ISNA+ = $1(1.0 \%) ;$ na-MCI ISNA- =0 $(0.0 \%)$ 
Table 5: Neuropsychological performances of MCI types with at least one ISNA (ISNA+) and without ISNA (ISNA-)

\begin{tabular}{|c|c|c|c|c|c|c|c|c|c|c|c|c|}
\hline & \multicolumn{2}{|c|}{ a-MCI $(n=375)$} & \multirow[b]{3}{*}{$p$ value } & \multicolumn{2}{|c|}{ a-MCImd $(n=504)$} & \multirow[b]{3}{*}{$p$ value } & \multicolumn{2}{|c|}{ na-MCI $(n=229)$} & \multirow[b]{3}{*}{$p$ value } & \multicolumn{2}{|c|}{ na-MCImd $(n=142)$} & \multirow[b]{3}{*}{$p$ value } \\
\hline & ISNA+ & ISNA- & & ISNA+ & ISNA- & & ISNA+ & ISNA- & & ISNA+ & ISNA- & \\
\hline & $\begin{array}{c}n=299 \\
(79.7)\end{array}$ & $n=76$ & & $\begin{array}{c}n=457 \\
(90.7)\end{array}$ & $n=47(9.3)$ & & $\begin{array}{c}n=188 \\
(82.1)\end{array}$ & $n=41(17.9)$ & & $\begin{array}{c}n=132 \\
(93.0)\end{array}$ & $n=10(7.0)$ & \\
\hline \multicolumn{13}{|c|}{ Neuropsychological performances } \\
\hline $\begin{array}{l}\text { MMSE, (median, } \\
\text { IQR) }\end{array}$ & $27.0,[25,28]$ & $27.0,[26,29]$ & $<0.001$ & $25.0,[25,26]$ & $26.0,[25,27]$ & 0.147 & $27.0,[26,28]$ & $27.0,[26,28]$ & 0.309 & $26.0,[25,27]$ & $\begin{array}{c}26.5,[25.3, \\
27.8]\end{array}$ & 0.314 \\
\hline \multicolumn{13}{|c|}{ Cognitive domain $z$ scores (median, IQR) } \\
\hline Memory & $-0.196(0.212)$ & $-0.174(0.180)$ & 0.101 & $|-0.277(0.322)|$ & $|-0.204(0.288)|$ & 0.147 & $0.108(0.400)$ & $0.121(0.341)$ & 0.753 & $0.127(0.493)$ & $0.177(0.708)$ & 0.174 \\
\hline Attention & $0.100(0.703)$ & $0.287(0.754)$ & 0.034 & $-0.102(1.092)$ & $-1.042(1.082)$ & 0.995 & $-0.630(1.211)$ & $|-0.341(1.322)|$ & 0.195 & $-1.249(0.577)$ & $-1.075(0.312) \mid$ & 0.375 \\
\hline Executive & $0.149(0.727)$ & $0.292(0.661)$ & 0.011 & $-0.330(1.191)$ & $-1.271(1.129)$ & 0.754 & $-0.385(1.401)$ & $|-0.364(1.447)|$ & 0.980 & $-1.382(0.681)$ & $-1.065(1.123) \mid$ & 0.124 \\
\hline Language & $0.139(0.713)$ & $0.445(0.679)$ & $<0.001$ & $-0.900(1.798)$ & $-0.156(2.012)$ & 0.004 & $-0.030(0.821)$ & $0.161(0.624)$ & 0.062 & $-0.950(1.871)$ & $-1.013(2.023)$ & 0.812 \\
\hline Constructional & $0.144(0.926)$ & $0.210(1.058)$ & 0.624 & $-0.385(1.323)$ & $-0.120(1.190)$ & 0.092 & $-0.120(0.926)$ & $|-0.012(1.190)|$ & 0.229 & $-0.385(1.620)$ & $-0.319(1.587) \mid$ & 0.809 \\
\hline Visuospatial & $0.478(0.895)$ & $0.478(0.895)$ & 0.868 & $0.030(1.342)$ & $0.030(1.342)$ & 0.147 & $0.478(1.342)$ & $0.478(1.789)$ & 0.399 & $0.030(1.789)$ & $0.925(0.671)$ & 0.062 \\
\hline
\end{tabular}

MCI = mild cognitive impairment; ISNA = isolated, subtle neurological abnormalities; a-MCI = amnestic mild cognitive impairment single domain; a-MCImd = amnestic mild cognitive impairment

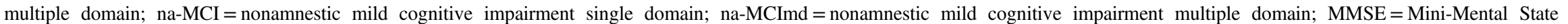
Examination.

Data presented are median, interquartile range (IQR), for continuous data, and number (\%) for categorical data.

Tests $F$ and $X^{2}$ were performed across the ISNA+ and ISNA- of each MCI type.

Bold values indicate significance at $p \leq 0.05$. 
Table 6: Carotid ultrasonography and imaging findings of MCI types with at least one ISNA (ISNA+) and without ISNA (ISNA-)

\begin{tabular}{|c|c|c|c|c|c|c|c|c|c|c|c|c|}
\hline & \multicolumn{2}{|c|}{ a-MCI $(n=375)$} & \multirow[b]{3}{*}{$p$ value } & \multicolumn{2}{|c|}{ a-MCImd $(n=504)$} & \multirow[b]{3}{*}{$p$ value } & \multicolumn{2}{|c|}{ na-MCI $(n=229)$} & \multirow[b]{3}{*}{$p$ value } & \multicolumn{2}{|c|}{ na-MCImd $(n=142)$} & \multirow[b]{3}{*}{$p$ value } \\
\hline & \multirow{2}{*}{$\begin{array}{c}\text { ISNA+ } \\
n=299 \\
(79.7)\end{array}$} & \multirow{2}{*}{$\begin{array}{c}\text { ISNA- } \\
n=76(20.3)\end{array}$} & & \multirow{2}{*}{$\begin{array}{c}\text { ISNA+ } \\
n=457 \\
(90.7)\end{array}$} & \multirow{2}{*}{$\begin{array}{c}\text { ISNA- } \\
n=47(9.3) \\
\end{array}$} & & \multirow{2}{*}{$\begin{array}{c}\text { ISNA+ } \\
n=188 \\
(82.1)\end{array}$} & \multirow{2}{*}{$\begin{array}{c}\text { ISNA- } \\
n=41(17.9)\end{array}$} & & \multirow{2}{*}{$\begin{array}{c}\text { ISNA+ } \\
n=132 \\
(93.0) \\
\end{array}$} & \multirow{2}{*}{$\begin{array}{l}\text { ISNA- } \\
n=10(7.0)\end{array}$} & \\
\hline & & & & & & & & & & & & \\
\hline \multicolumn{13}{|c|}{ Carotid ultrasonography* } \\
\hline IMT & $254(86.4)$ & $37(49.3)$ & $<0.001$ & $407(90.4)$ & $33(76.7)$ & 0.012 & $153(81.8)$ & $24(61.5)$ & 0.010 & $114(86.4)$ & $5(55.6)$ & 0.047 \\
\hline SICA $(\geq 50 \%)$ & $9(3.1)$ & $0(0.0)$ & 0.265 & $21(4.7)$ & $0(0.0)$ & 0.293 & $6(3.2)$ & $0(0.0)$ & 0.558 & $7(5.3)$ & $0(0.0)$ & 1.000 \\
\hline \multicolumn{13}{|l|}{ Imaging findings } \\
\hline WMH-SC & $81(27.1)$ & $9(11.8)$ & 0.009 & $138(30.2)$ & $12(25.5)$ & 0.618 & 65 (34.6) & $3(7.3)$ & 0.001 & $57(43.2)$ & $0(0.0)$ & 0.019 \\
\hline WMH-BG & $24(8.0)$ & $1(1.3)$ & 0.066 & $53(11.6)$ & $0(0.0)$ & 0.027 & $19(10.1)$ & $0(0.0)$ & 0.070 & $16(12.1)$ & $0(0.0)$ & 0.516 \\
\hline WMH-INF & $6(2.0)$ & $0(0.0)$ & 0.464 & $9(2.0)$ & $0(0.0)$ & 0.695 & $10(5.3)$ & $0(0.0)$ & 0.276 & $5(3.8)$ & $0(0.0)$ & 1.000 \\
\hline WMH-T & $86(28.8)$ & $9(11.8)$ & 0.004 & $146(31.9)$ & $12(25.5)$ & 0.461 & 65 (34.6) & $3(7.3)$ & 0.001 & $57(43.2)$ & $0(0.0)$ & 0.019 \\
\hline WMH-PV & $173(57.9)$ & $17(22.4)$ & $<0.001$ & $274(60.0)$ & $22(46.8)$ & 0.112 & $124(66.0)$ & $6(14.6)$ & $<0.001$ & $86(65.2)$ & $0(0.0)$ & $<0.001$ \\
\hline Lacunes-SC & $69(23.1)$ & $12(15.8)$ & 0.221 & $119(26.0)$ & $11(23.4)$ & 0.827 & $46(24.5)$ & $2(4.9)$ & 0.010 & $38(28.8)$ & $0(0.0)$ & 0.107 \\
\hline Lacunes-BG & $54(18.1)$ & $3(4.0)$ & 0.004 & $95(20.8)$ & $4(8.5)$ & 0.068 & $26(13.8)$ & $0(0.0)$ & 0.024 & $21(15.9)$ & $0(0.0)$ & 0.366 \\
\hline Lacunes-INF & $9(3.0)$ & $3(4.0)$ & 0.960 & $20(4.4)$ & $3(6.4)$ & 0.794 & $6(3.7)$ & $0(0.0)$ & 0.451 & $3(3.0)$ & $0(0.0)$ & 1.000 \\
\hline Lacunes- $\mathrm{T}$ & $108(36.1)$ & $16(21.1)$ & 0.018 & $177(38.7)$ & $16(34.0)$ & 0.637 & $63(33.3)$ & $2(4.9)$ & $<0.001$ & $50(37.9)$ & $0(0.0)$ & 0.038 \\
\hline SVD+ & $104(55.3)$ & $4(9.8)$ & \multirow{2}{*}{$<0.001$} & $254(55.6)$ & $24(51.1)$ & \multirow{2}{*}{0.813} & $104(55.3)$ & $4(9.8)$ & \multirow{2}{*}{$<0.001$} & $86(65.2)$ & $0(0.0)$ & \multirow{2}{*}{$<0.001$} \\
\hline SVD- & $84(44.7)$ & $37(90.2)$ & & $203(44.4)$ & $23(48.9)$ & & $84(44.7)$ & $37(90.2)$ & & $46(34.8)$ & $10(100.0)$ & \\
\hline \multicolumn{13}{|c|}{ Measures of brain atrophy } \\
\hline $\mathrm{BCr}$ & $0.15 \pm 0.02$ & $0.12 \pm 0.02$ & $<0.001$ & $0.15 \pm 0.02$ & $0.14 \pm 0.02$ & 0.357 & $0.14 \pm 0.02$ & $0.13 \pm 0.02$ & $<0.001$ & $0.15 \pm 0.02$ & $0.13 \pm 0.02$ & 0.003 \\
\hline $\mathrm{LVBr}$ & $2.45 \pm 0.49$ & $2.13 \pm 0.43$ & $<0.001$ & $2.53 \pm 0.46$ & $2.42 \pm 0.56$ & 0.133 & $2.40 \pm 0.44$ & $2.18 \pm 0.52$ & 0.005 & $2.57 \pm 0.48$ & $2.30 \pm 0.56$ & 0.100 \\
\hline
\end{tabular}

MCI = mild cognitive impairment; ISNA = isolated, subtle neurological abnormalities; a-MCI = amnestic mild cognitive impairment single domain; a-MCImd = amnestic mild cognitive impairment multiple domain; na-MCI = nonamnestic mild cognitive impairment single domain; na-MCImd = nonamnestic mild cognitive impairment multiple domain; IMT = intimal-medial thickness; SICA = stenosis of the internal carotid artery; $\mathrm{WMHs}=$ white matter hyperintensities; $\mathrm{SC}=$ deep/subcortical; $\mathrm{BG}$ basal ganglia; INF = infratentorial; $\mathrm{T}=$ total; $\mathrm{PV}=$ periventricular; $\mathrm{SVD}$ $+=$ small vessel disease (presence of $\mathrm{WMH}$ and lacunes with a score $\geq 2$ ); $\mathrm{SVD}-=$ small vessel disease (presence of $\mathrm{WMH}$ and lacunes with a score $\leq 1$ ); $\mathrm{BCr}=$ bicaudate ratio, $\mathrm{LVBr}=$ lateral ventricles to brain ratio.

*Missing data: a-MCI ISNA+ =5 (2.0\%); a-MCI ISNA- = 1 (1.0\%); a-MCImd ISNA+ =7 (2.0\%); a-MCImd ISNA-= 4 (8.0\%); na-MCI ISNA+=1 (1.0\%); na-MCI ISNA-=2 (5.0\%); na-MCImd ISNA $-=1$ (10.0\%).Data presented are number (\%) for categorical and mean \pm SD for continuous data. Tests $F$ and $X^{2}$ were performed across the ISNA+ and ISNA- of each MCI type. Bold values indicate significance at $p \leq 0.05$. 
Table 7: Association between VRF and VD summary scores, APOE $€ 4$ carriers, IMT, topographical location of SVD, WMH-PV, $\mathrm{BCr}, \mathrm{LVBr}$, and the risk of having at least one ISNA in individual MCI types

\begin{tabular}{|c|c|c|c|c|}
\hline & a-MCI & a-MCImd & na-MCI & na-MCImd \\
\hline & OR $(95 \% \mathrm{CI})$ & OR $(95 \% \mathrm{CI})$ & OR $(95 \%$ CI $)$ & OR $(95 \%$ CI $)$ \\
\hline Age & $1.031(1.004-1.058)$ & $1.016(0.982-1.050)$ & $1.028(0.992-1.066)$ & $1.007(0.947-1.071)$ \\
\hline Sex (female) & $1.077(1.015-1.144)$ & $1.040(0.980-1.102)$ & $0.987(0.906-1.074)$ & $1.013(0.987-1.040)$ \\
\hline Education & $0.995(0.944-1.048)$ & $0.986(0.926-1.050)$ & $0.995(0.919-1.078)$ & $0.991(0.899-1.092)$ \\
\hline VRF summary score & $1.016(0.922-1.121)$ & $1.007(0.909-1.115)$ & $1.046(0.911-1.200)$ & $1.039(0.971-1.112)$ \\
\hline VD summary score & $1.181(1.098-1.270)$ & $0.960(0.890-1.037)$ & $1.111(1.008-1.224)$ & $1.045(1.009-1.083)$ \\
\hline APOE $€ 4$ carriers & $1.527(1.452-1.607)$ & $1.165(1.118-1.214)$ & $0.982(0.904-1.068)$ & $1.051(1.026-1.076)$ \\
\hline Intimal-medial tickness & $1.527(1.452-1.606)$ & $1.369(1.311-1.429)$ & $1.148(1.062-1.240)$ & $1.163(1.140-1.187)$ \\
\hline WMH-PV & $1.367(1.300-1.437)$ & $0.948(0.895-1.003)$ & $1.584(1.459-1.720)$ & $1.143(1.115-1.172)$ \\
\hline Frontal SVD & $1.164(1.100-1.232)$ & $0.967(0.913-1.024)$ & $1.545(1.427-1.672)$ & $1.160(1.129-1.192)$ \\
\hline Parieto-occipital SVD & $1.223(1.172-1.277)$ & $1.002(0.953-1.054)$ & $1.303(1.221-1.390)$ & $1.105(1.080-1.131)$ \\
\hline Lateral temporal SVD & $1.140(1.104-1.177)$ & $1.159(1.115-1.205)$ & $1.198(1.145-1.254)$ & $1.084(1.063-1.105)$ \\
\hline Basal Ganglia SVD & $1.299(1.243-1.358)$ & $1.311(1.247-1.379)$ & $1.518(1.433-1.609)$ & $1.097(1.074-1.122)$ \\
\hline $\mathrm{BCr}$ & $1.156(1.126-1.187)$ & $1.319(1.293-1.346)$ & $1.658(1.610-1.706)$ & $1.324(1.312-1.336)$ \\
\hline $\mathrm{LVBr}$ & $1.131(1.070-1.196)$ & $1.062(1.008-1.120)$ & $1.096(1.012-1.187)$ & $1.052(1.028-1.076)$ \\
\hline
\end{tabular}

VRFs = vascular risk factors; VDs = vascular diseases; APOE = apolipoprotein E; IMT = intimal-medial thickness ; WMHs = white matter hyperintensities; $\mathrm{PV}=$ periventrivular; $\mathrm{SVD}=$ small vessel disease (presence of $\mathrm{WMH}$ and lacunes with scores $\geq 2$ ); $\mathrm{BCr}=$ bicaudate ratio; $\mathrm{LVBr}=$ lateral ventricle to brain ratio; ISNAs = isolated, subtle neurological abnormalities; $\mathrm{OR}=$ odd ratio; $\mathrm{CI}=$ confidence interval; a-MCI = amnestic mild cognitive impairment single domain; a-MCImd = amnestic mild cognitive impairment multiple domain; na-MCI = nonamnestic mild cognitive impairment single domain; na-MCImd = nonamnestic mild cognitive impairment multiple domain.

For each MCI types, association of the variables with ISNA categories was estimated using logistic regression analysis with adjustments for age, sex, and education (years).

Bold values indicate significance at $p \leq 0.05$.

increased by $36.7 \%, 58.4 \%$, and $14.3 \%$ the probability of having at least one ISNA in a-MCI, na-MCI, and na-MCImd, respectively. The presence of SVD in the frontal region increased the risk of having at least one ISNA in a-MCI $(16.4 \%)$, na-MCI $(54.5 \%)$, and na-MCImd (16\%) types. The presence of SVD in the parieto-occipital region increased the risk of having at least one ISNA in a-MCI, na-MCI, and na-MCImd by $22.3 \%, 30.3 \%$, and $10.5 \%$, respectively. The presence of SVD in the lateral temporal region increased the risk of having at least one ISNA in a-MCI, a-MCImd, na-MCI, and na-MCImd MCI by $14.0 \%$, $15.9 \%, 19.8 \%$, and $8.4 \%$, respectively. The presence of SVD in the basal ganglia increased the risk of having at least one ISNA in a-MCI, a-MCImd, na-MCI, and na-MCImd by $29.9 \%, 31.1 \%$, $51.8 \%$, and $9.7 \%$, respectively. $\mathrm{BCr}$ and $\mathrm{LVBr}$ resulted associated with all the MCI types. At the increment of a single percentage point of $\mathrm{BCr}$, the probability of having at least one ISNA increased by $15.6 \%$ in a-MCI, $31.9 \%$ in a-MCImd, $65.8 \%$ in na-MCI, and $32.4 \%$ in na-MCImd. At the increment of a single percentage point of $\mathrm{LVBr}$, the odds of having at least one ISNA increased by $13.1 \%$ in a-MCI, $6.2 \%$ in a-MCImd, $9.6 \%$ in naMCI, and $5.2 \%$ in na-MCImd.

\section{Discussion}

The frequency of ISNA detected in subjects with MCI was greater $(86 \%)$ than that found in $\mathrm{NCH}$ aging individuals
$(57.2 \%) .{ }^{20}$ In all MCI types, and in all age classes, PRs were the ISNA most frequently encountered, followed by Cs, MPS, and CLs. All ISNA categories increased with age and were presented by both the amnestic and nonamnestic MCI types, particularly by those multiple domain, with the exception of Cs and PR that in the old-oldest old subjects were more common among the MCI types single domain.

Copious data of the literature underline the importance of midlife vascular risks and $\mathrm{A} \beta$ burden to neurodegenerative processes and to the development of cognitive decline in older adults. In CN individuals, midlife VRFs accelerate structural brain aging ${ }^{42}$ and are associated with greater prospective cognitive decline, ${ }^{43}$ current and later-life smaller brain volumes, ${ }^{44}$ and risk of dementia. ${ }^{45}$ Further, midlife but not later-life exposure to VRF is important also for $A \beta$ deposition, as shown by the fact that having two or more midlife VRFs compared with none is significantly associated with elevated $A \beta$ deposition $(61.2 \%$ vs $30.8 \%) .{ }^{46}$ In addition, in $\mathrm{CN}$ and $\mathrm{MCI}$ individuals, VRFs interact with $\mathrm{A} \beta$ to reduce cortical thickness in frontotemporal and parietal regions vulnerable to $\mathrm{AD}^{47}$ and are associated with prospective cognitive decline, both alone and synergistically with $\mathrm{A} \beta$ burden. ${ }^{48}$ However, VRF summary score was not associated with ISNAs in any of the four MCI types, and VD summary score increased the probability of having at least one ISNA in the MCI types single domain and poorly in the na-MCImd. These data need attention. A high vascular risk burden at younger ages is indeed indicative of early vascular aging, ${ }^{49}$ 
but in the later years of life, it is less relevant regarding the MCI typology since vascular and neurodegenerative processes have already occurred at younger ages when the MCI typology is likely to be of single domain type. The fact that subjects with MCI types multiple domain were older than subjects with MCI types single domain supports this hypothesis. IMT increased the probability of having at least one ISNA in all MCI types, and the risk was greater for the amnestic MCI types than for the nonamnestic types. These results are in agreement with a previous study showing that IMT is associated with $\mathrm{WMH}$, infarcts, brain atrophy, and with poor cognitive performance particularly in the executive function. ${ }^{50}$ Further, IMT significantly increases the risk of conversion of a-MCI to dementia. ${ }^{51} \mathrm{WMH}-\mathrm{PV}$ increased greatly the probability of having at least one ISNA in MCI types single domain and in the na-MCImd. It has been shown that WMH-PV are associated with elevated $\mathrm{A} \beta$ deposition independent from age and presence of APOE $€ 4$ allele ${ }^{52}$ and induce thinning of prefrontal, parietal, temporal cortices, anterior insula, and atrophy of the caudate nuclei, ${ }^{14}$ and cognitive decline through the cortical atrophy of the above disconnected regions. ${ }^{19}$ Therefore, it is reasonable to suspect that even in our MCI types, WMH-PV may also have induced atrophy of the caudate nuclei, and thinning of the frontal, parietal, and temporal cortices through likely disruption of periventricular long associating tracts.

Overall, SVD at different topographical locations and $\mathrm{BCr}$ greatly increase the risk of having ISNA in all the MCI types. Given that cortex, cerebellum, and BG are strictly interconnected ${ }^{53}$ it is likely that ISNAs are the by-product of the disconnection of the cortical-cerebellar-basal ganglia-thalamocortical circuits induced by vascular and degenerative processes. It is also likely that the caudate atrophy and the disruption of the internal circuits of BG may have induced an excessive inhibition to its output nuclei. As a consequence, the inhibitory drive to thalamus may have led to bradykinesia and that to brainstem structures controlling postural muscle tone and locomotion may have led to rigidity and gait/balance/axial dysfunction, respectively, ${ }^{54}$ while the inhibition of the physiological inhibitor control of lower brainstem centers on stereotyped motor responses ${ }^{55}$ may have led to the reappearance of PRs.

Nevertheless, the above hypotheses underpinning the vascular contribution to ISNA do not fully explain their presentation in the various MCI types. Among the amnestic MCI types, 39\% $(n=342)$ of subjects ISNA+ were SVD- and $5 \%(n=45)$ of subjects ISNA- were SVD+. Similarly, among the nonamnestic MCI types, 51\% $(n=190)$ of subjects ISNA+ were SVD- and $35 \%(n=130)$ of subjects ISNA- were SVD+. These conflicting data suggest that co-occurring factors other than vascular contribute to the presentation of ISNA. The APOE $\epsilon 4$ allele can be one of these factors. In the present study, the APOE $€ 4$ carriers were indeed over-represented relative to other studies, probably because the CogItA study assessed essentially subjects referred to the memory clinic, making the sample vulnerable to selection. Overall, APOE $€ 4$ carriers were more common among subjects ISNA+ than subjects ISNA- in all MCI types, and being $\epsilon 4$ carrier increased the probability of having at least one ISNA greatly in the amnestic MCI types and scarcely in the nonamnestic MCI types, a finding in agreement with the notion that compared to non- $\epsilon 4$ carriers, $\mathrm{MCI} \epsilon 4$ carriers have frequently the amnestic phenotype. ${ }^{56}$ The presence of APOE $€ 4$ allele in nonamnestic MCI types is not surprising. Along with age, APOE $€ 4$ allele is a significant predictor of amyloidosis. More than half of all MCI types is $\mathrm{A} \beta$ positive,${ }^{57}$ and APOE $\epsilon 4$ carriers are 2-3 times more likely to be amyloid positive than APOE $€ 4$ noncarriers. ${ }^{6}$ Subjects with MCI have elevated $\mathrm{A} \beta$ deposition in frontal, parietal, temporal, and posterior cingulate cortices suggestive of early $\mathrm{AD}$ process, ${ }^{58}$ and those converting to $\mathrm{AD}$ have a greater $A \beta$ deposition in these regions, as well as in the putamen and in the caudate nuclei as compared to nonconverters. ${ }^{59}$ Furthermore, in subjects with MCI, the presence of the APOE e4 allele is more frequent in the converters than in the nonconverters. ${ }^{60}$ Therefore, it is reasonable to suspect that subjects of all four MCI types carrying the APOE $\epsilon 4$ allele were also $A \beta$ positive and that subjects ISNA+ being more APOE $\epsilon 4$ carriers than subjects ISNA- were candidates to convert to dementia faster than subjects ISNA-.

\section{Limitations of the Study}

Some limitations of our study are worth noting. First, CSF biomarkers of $\mathrm{A} \beta$ and tau and advanced imaging techniques up to now are not fully available in our country, particularly in a clinical setting. So, we do not know the distribution of $A \beta$ and tau in subjects ISNA+ and ISNA- of the various MCI types. Second, we assessed cortical and subcortical atrophy using linear measurements well aware that they are rather crude estimates of brain atrophy. However, it has been shown that the $\mathrm{BCr}$ is a reliable marker of caudate atrophy ${ }^{61}$ and that ventricular enlargement is a feasible, even if nonspecific, surrogate marker of neurodegeneration in MCI and $\mathrm{AD} .{ }^{16}$ Third, we did not estimate WMH volumetrically, but visually. However, it has been shown that WMH evaluated with visual scales correlates well with WMH volumetry. ${ }^{62}$ Fourth, perhaps, we underestimated the magnitude of cerebral SVD in our cohort because we evaluated WMHs and lacunes only. Fifth, the generalizability of our results is limited because the patients have been selected in a hospital setting. Sixth, in the present paper, there is no mention of the ISNAs in neurologically and $\mathrm{CN}$ subjects because data on this topic have been already published. ${ }^{20}$ Lastly, the cross-sectional design of our study does not allow causal inferences.

\section{Conclusion}

ISNAs are likely to have a multifactorial origin, increase with age, and are presented by both the amnestic and nonamnestic MCI types, particularly by those multiple domain, and carrying the APOE $€ 4$ allele. Further, subjects ISNA+ perform less than subjects ISNA- in almost all nonmemory domains. Given that cortical and subcortical vascular and atrophic processes contribute to ISNAs, their presence in individuals with MCI must alert the practitioners to target timely interventions to slowing cognitive decline and delay progression of MCI to dementia. Longer prospective population-based studies are needed to clarify to what extent the presentation of ISNAs in middle-aged and older MCI individuals represents an additive risk for the conversion to dementia.

\section{ACKNOWLEDGEMENTS}

We gratefully thank all participants, as well as the neurologists and the neuropsychologists who over time collected patients data. 


\section{DisClOSURES}

All the authors hereby declare that they have nothing to disclose.

\section{Statement of Authorship}

$\mathrm{CC}$ and $\mathrm{RC}$ were responsible for the study's concept and design, data managements, and record linkage. GS and GC did the statistical analysis. CC, PT, CP, DA, and RC contributed to the analysis and interpretation of the data.

$\mathrm{CC}$ wrote the paper. All co-authors edited the paper and approved its final version.

\section{ReFERENCES}

1. Petersen RC, Smith GE, Waring SC, Ivnik RJ, Tangalos EG, Kokmen E. Mild cognitive impairment: clinical characterization and outcome. Arch Neurol. 1999;56:303-8.

2. Petersen RC. Mild cognitive impairment as a diagnostic entity. J Intern Med. 2004;256:183-94.

3. Jack RC Jr. Brain atrophy on magnetic resonance imaging as a biomarker of neurodegeneration. JAMA Neurol. 2006;73:1179-82.

4. McKhann GM, Knopman DS, Chertkow H, et al. The diagnosis of dementia due to Alzheimer's disease: recommendations from the National Institute on Aging-Alzheimer's Association workgroups on diagnostic guide-lines for Alzheimer's disease. Alzheimers Dement. 2001;7:263-9.

5. Albert MS, Dekosky ST, Dickson D, et al. The diagnosis of mild cognitive impairment due to Alzheimer's disease: recommendations from the National Institute on Aging and Alzheimer's Association workgroups on diagnostic guidelines for Alzheimer's disease. Alzheimers Dement. 2011;7:270-9.

6. Jansen WJ, Ossenkoppele R, Knol DL, et al. Prevalence of cerebral amyloid pathology in persons without dementia: a meta-analysis. JAMA 2015;313:1924-38.

7. Jack CR Jr, Wiste HJ, Schwarz CG, et al. Longitudinal tau PET in ageing and Alzheimer's disease. Brain. 2018;141:1517-28.

8. Petersen RC, Aisen P, Boeve BF, et al. Criteria for mild cognitive impairment due to Alzheimer disease in the community. Ann Neurol. 2013;74:199-208.

9. Pantoni L. Cerebral small vessel disease: from pathogenesis and clinical characteristics to therapeutic challenges. Lancet Neurol. 2010;9:689-701.

10. Luchsinger JA, Brickman AM, Reitz C, et al. Subclinical cerebrovascular disease in mild cognitive impairment. Neurology. 2009;73:450-6.

11. Gorelick PB, Scuteri A, Black SE, et al. Vascular contributions to cognitive impairment and dementia: a statement for healthcare professionals from the American Heart Association/American Stroke Association. Stroke. 2011;42:2672-713.

12. Wardlaw JM, Smith C, Biessels GJ, et al. Neuroimaging standards for research into small vessel disease and its contribution to ageing and neurodegeneration. Lancet Neurol. 2013;12:822-38.

13. Reijner YD, Freeze WM, Leemans A, Biessels GJ. The effect of lacunar infarcts on white matter tract integrity. Stroke. 2013;44: 2019-2021.

14. Lambert C, Narean JS, Benjamin P, Zeestraten E, Barrick TR, Markus HS. Characterising the grey matter correlates of leukoaraiosis in cerebral small vessel disease. Neuroimage Clin. 2015;9:194-205

15. Thong JY, Hilal S, Wang Y, et al. Association of silent lacunar infarct with brain atrophy and cognitive impairment. J Neurol Neurosur Ps. 2013;84:1219-25.

16. Madsen SK, Gutman BA, Joshi SH, et al. Mapping ventricular expansion onto cortical gray matter in older adults. Neurobiol Aging. 2014;36(Suppl 1):S32-S41.

17. Raz N, Lindenberger U, Rodrigue KM, et al. Regional brain changes in aging healthy adults: general trends, individual differences and modifiers. Cereb Cortex. 2005;15:1676-89.
18. Habes M, Erus G, Toledo JB, et al. White matter hyperintensities and imaging patterns of brain ageing in the general population. Brain. 2016;139:1164-79.

19. Rizvi B, Narkhede A, Last BS, et al. The effect of white matter hyperintensities on cognition is mediated by cortical atrophy. Neurobiol Aging. 2018;64:25-32.

20. Camarda C, Torelli P, Camarda R, Battaglini J, Gagliardo C, Monastero R. Isolated, subtle, neurological abnormalities in neurologically and cognitively healthy aging subjects. J Neurol. 2015;262:1328-39.

21. Louis ED, Schupf N, Manly J, Marder K,Tang MX, Mayeux R. Association between mild parkinsonian signs and mild cognitive impairment in a community. Neurology. 2005;64:1157-61.

22. Boyle PA, Wilson RS, Aggarwal NT, et al. Parkinsonian signs in subjects with mild cognitive impairment. Neurology. 2005;65: 1901-6.

23. Folstein MF, Folstein SE, McHugh PR. Mini-mental State: a practical method for grading the cognitive state of patients for the clinician. J Psychiatr Res. 1975;12:189-98.

24. Morris JC. Clinical dementia rating: a reliable and valid diagnostic and staging measure for dementia of the Alzheimer type. Int Psychogeriatr. 1997;9:173-6.

25. Katz S, Ford AB, Moskowitz RW, Jackson BA, Jaffe MW. Studies of illness in the aged. The index of ADL: a standardized measure of biological and psychosocial function. JAMA. 1963;185:914-9.

26. Lawton MP, Brody EM. Assessment of older people: selfmaintaining and instrumental activities of daily living. Gerontologist. 1969;9:179-86.

27. McKeith IG, Galasko D, Kosaka K, et al. Consensus guidelines for the clinical and pathologic diagnosis of dementia with Lewy bodies (DLB): report of the Consortium on DLB International Workshop. J Alzheimers Dis. 2006;9:417-23.

28. Brun A, Englund B, Gustafson L, et al. Clinical and neuropathological criteria for frontotemporal dementia. The Lund and Manchester Groups. J Neurol Neurosur Psychiatry. 1994;57:416-8.

29. Camarda C, Torelli P, Pipia C, Azzarello D, Battaglini I, Sottile G, Cilluffo G, Camarda R. Nociceptive primitive reflexes in neurologically and cognitively healthy aging subjects. Canad J Neurol Sci. 2019;46:199-208

30. Hixson JE, Vernier DT. Restriction isotyping of human apolipoprotein $\mathrm{E}$ by gene amplification and cleavage with Hhal. J Lipid Res. 1982;31:545-8.

31. Rossor MN. Snouting, poting and rooting. Pract Neurol. 2001; $1: 119-21$

32. Schott JM, Rossor MN. The grasp and other primitive reflexes. J Neurol Neurosur Psychiatry. 2003;74:558-60.

33. Louis ED, Bennett DA. Mild Parkinsonian Signs: an overview of an emerging concept. Mov Disord. 2007;22:1681-88.

34. Fahn S, Elton RL and the members of the UPDRS development committee. Unified Parkinson's disease rating scale. In: Fahn S, Marsden CD, Goldstein M, Calne DB, editors. Recent developments in Parkinson's disease. London: Macmillan Healthcare Information; 1987, pp. 153-63.

35. Camarda C, Pipia C, Azzarello D, et al. Vascular risk factors, vascular diseases, and imaging findings in a hospital-based cohort of mild cognitive impairment types. Current Alzheimer Dis. 2018;15:679-90.

36. Carlesimo GA, Caltagirone C, Gainotti G. The mental deterioration battery: normative data, diagnostic reliability and qualitative analyses of cognitive impairment: the Group for the Standardization of the Mental Deterioration Battery. Eur Neurol. 1996;36:378-84.

37. Wahlund LO, Barkhof F, Fazekas F, et al. A new rating scale for age-related white matter changes applicable to MRI and CT. Stroke. 2001;32:1318-22.

38. Fazekas F, Chawluk JB, Alavi A, Hurtig HI, Zimmerman RA. MR signal abnormalities at $1.5 \mathrm{~T}$ in Alzheimer's dementia and normal aging. AJR Am J Neuroradiol. 1987;8:421-6.

39. Hoerl AE, Kennard RW. Ridge regression: biased estimation for nonorthogonal problems. Technometrics. 1970;12:55-67.

40. El-Dereny M, Rashwan NI. Solving multicollinearity problem using ridge regression models. Int $\mathrm{J}$ Contemp Math Sciences. 2011;6:585-600. 
41. Goeman JJ. L1 penalized estimation in the Cox proportional hazards model. Biom J. 2010;52:70-84.

42. Debette S, Seshadri S, Beiser A, et al. Midlife vascular risk factor exposure accelerates structural brain aging and cognitive decline. Neurology. 2011;77:461-8.

43. Gottesman RF, Schneider AL, Albert M, et al. Midlife hypertension and 20-year cognitive change: the atherosclerosis risk in communities neurocognitive study. JAMA Neurol. 2014;71:1218-27.

44. Pase MP, Davis-Plourde K, Himali JJ, et al. Vascular risk at younger ages most strongly associates with current and future brain volume. Neurology. 2018;91:1479-86.

45. Whitmer RA, Gunderson EP, Quesenberry CP Jr, Zhou J, Yaffe K. Bodymass index in midlife and risk of Alzheimer disease and vascular dementia. Curr Alzheimer Res. 2007;4:103-9.

46. Gottesman RF, Schneider AL, Zhou Y, et al. Association between midlife vascular risk factors and estimated brain amyloid deposition. JAMA. 2017;317:1443-50.

47. Villeneuve $S$, Reed BR, Madison CM, et al. Vascular risk and A $\beta$ interact to reduce cortical thickness in $\mathrm{AD}$ vulnerable brain regions. Neurology. 2014;83:40-7.

48. Rabin JS, Schultz AP, Hedden T, et al. Interactive associations of vascular risk and $\beta$-amyloid burden with cognitive decline in clinically normal elderly individuals. Findings from the Harvard Aging Brain Study. JAMA Neurol. 2018;75:1124-31.

49. Nilsson PM. Early vascular aging (EVA): consequences and prevention. Vasc Health Risk Manag. 2008;4:547-52.

50. Romero JR, Beiser A, Seshadri S, et al. Carotid artery atherosclerosis, MRI indices of brain ischemia, aging, and cognitive impairment: the Framingham study. Stroke. 2009;40:1590-1596.

51. Viticchi G, Falsetti L,Vernieri F, et al. Vascular predictors of cognitive decline in patients with mild cognitive impairment. Neurobiol Aging. 2012;33:1127. e1-9.
52. Marnane M, Al-Jawadi OO, Mortazavi S, et al. Periventricular hyperintensities are associated with elevated cerebral amyloid. Neurology. 2016;86:1-9.

53. Caligiore D, Strick PL, Jörntell H, et al. Consensus paper: towards a systems-levelview of cerebellar function: the interplay between cerebellum, basal ganglia, and cortex. Cerebellum. 2017;16:203-229.

54. Takakusaki K. Neurophysiology of gait: from the spinal cord to the frontal lobe. Mov Disord. 2013;28:1483-91.

55. Delwaide PJ, Dijeux L. Réflexes néonateaux et dyskinésies buccolinguo-faciales dans la démence sénile. Neonatal reflexes and bucco-linguo-facial dyskinesias in senile dementia. L'Actualité en Gérontologie. 1980;6:126-33.

56. Snowden JS, Stopford CL, Julien CL, et al. Cognitive phenotypes in Alzheimer's disease and genetic risk. Cortex. 2007;43: 835-845.

57. Wolk DA, Price JC, Saxton JA, et al. Amyloid imaging in mild cognitive impairment subtypes. Ann Neurol. 2009;65:557-68.

58. Kemppainen NM, Aalto S, Wilson IA, et al. PET amyloid ligand [C-11] PIB uptake is increased in mild cognitive impairment. Neurology. 2007;68:1603-6.

59. Koivunen J, Scheinin N., Virta JR, et al. Amyloid PET imaging in patients with mild cognitive impairment. A 2-year follow-up study. Neurology. 2011;76:1085-90.

60. Okello A, Koivunen J, Edison P, et al. Conversion of amyloid positive and negative MCI to AD over 3 years: an11C-PIB PET study. Neurology. 2009;73:754-60.

61. Doraiswamy PM, Patterson L, Na C, et al. Bicaudate index on magnetic resonance imaging: effects of normal aging. J Geriatr Psych Neurol. 1994;7:13-17.

62. Gao F, Swartz RH, Scheltens P, et al. Complexity of MRI White matter hyperintensity assessments in relation to cognition in aging and dementia from the Sunnybrook Dementia Study. J Alzheimers Dis. 2011;26:379-88. 